\title{
Contextualized Problem Solving: It's Effect on Students' Achievement, Conceptual Understanding and Mathematics Anxiety
}

\author{
Laila S. Lomibao ${ }^{1}$, Carmela J. Go Silk ${ }^{2}$, Charita A. Luna ${ }^{3}$ \\ ${ }^{1}$ University of Science and Technology of Southern Philippines, Lapasan, Cagayan de Oro City \\ ${ }^{2}$ Western Mindanao State University -Malangas Campus, Malangas, Zamboanga Sibugay \\ ${ }^{3}$ University of Science and Technology of Southern Philippines, Lapasan, Cagayan de Oro City
}

\begin{abstract}
The study determined the effect of contextualized problem solving on the students' achievement, conceptual understanding and mathematics anxiety of the second year Bachelor of Elementary Education students of Western Mindanao State University Malangas Campus. It employed pretest-posttest quasi-experimental design using a 10-item teacher-made word problem to assess the achievement and conceptual understanding of the students enrolled in Advanced Algebra and Trigonometry during the $1^{\text {st }}$ semester of school year 2016-2017. The school has only two sections, so one section was randomly assigned as the control group and the other as experimental group. Of the two groups, 12 participants were randomly selected for interview to validate the findings after the posttest. The one-way analysis of covariance (ANCOVA) was used to analyze the data. An analysis of students' solutions was done to verify the quantitative data on students' achievement and conceptual understanding. Results of the analysis revealed that the experimental group of students has significantly higher achievement, conceptual understanding and lower mathematics anxiety compared to the control group which is non-contextualized in approach. It was also found out that students' achievement significantly relate to their conceptual understanding from both the control and experimental groups. Hence, the researcher concludes that contextualized problem is effective in improving and enhancing students' problem solving achievement and conceptual understanding in terms of interpreting, applying and explaining algebra concepts. It has significantly reduced students' anxiety towards mathematics.
\end{abstract}

Keywords: contextualized problem solving, conceptual understanding, mathematics anxiety

\section{Introduction}

The persistent declining status of mathematical performance among students is not only local and national concern but also worldwide for the past two decades, (PISA, 2003). Sherman and Yard (2014) believed that there are many reasons why students fall below their expected level of mathematics achievement. When students were asked why they were not successful in learning mathematics, many replied that they never understood mathematics, or never liked the subject because it was too abstract and did not relate to them. Hence, different methodologies and researches have been conducted to address the problem. Recent local study on "Cognitive and Metacognitive Skills in Solving Word Problems in Algebra" revealed that the problem solving proficiency of the students is still in the developing level due to lack of mastery, misconceptions and lack of retention (Go Silk, 2012; Go Silk, Somblingo \& Go Silk, 2015). As mathematics teachers, the researchers are challenged by the low performance of the students in mathematics particularly in problem solving. It is the desire of this study to use contextualized problems in teaching problem solving to determine whether students could perform better if they could relate the problems to their daily life.

Various scholars recommend that students can develop thorough understandings of mathematical concepts through contextualized problem solving (Freudenthal, 1991). According to Hudson and Miller (2006), contextualized problems are presented in real-life format and solved through an activity with the use of manipulative. The purpose of using manipulative is to develop the conceptual understanding of the students and then use this conceptual understanding to develop and understand the use of formula at an abstract level. Students can demonstrate conceptual understanding if they can recognize, label, explain, interpret, represents concepts through diagrams, tables and graphs and apply the symbols of terms they represent for the concepts. Teachers of mathematics must create opportunities for students to transfer their conceptual understanding to new situations (NCTM, 2000).

Another challenge commonly experienced by students is mathematics anxiety. Mathematics anxiety is a feeling of tension and nervousness which interfere while manipulating and solving mathematical problems in a wide variety of mathematical tasks (Richardson \& Suinn, 1972).

Problem solving is an important vehicle to develop students' mathematics ability because it enhances critical thinking which is the ultimate goal in mathematics teaching. However, most undergraduate college students react emotionally and feel anxious when asked to solve problems which caused in their avoidance of mathematics that eventually led to the deterioration of their mathematics achievement (Dreger \& Aiken, 1957). This situation led this study which sought to investigate if contextualized problems in teaching problem solving could effectively decrease students' mathematics anxiety. 


\section{International Journal of Science and Research (IJSR) \\ ISSN (Online): 2319-7064}

Index Copernicus Value (2015): 78.96 | Impact Factor (2015): 6.391

In view of the above discussion, it is the desires of the researchers to use contextualize problems in teaching, to determine if it could improve students' problem solving skills, conceptual understanding, lessen mathematics anxiety and help alleviate their state of mathematics achievement.

\section{Theoretical Framework and Related Literature}

\subsection{Contextualized Problems Solving to Promote Conceptual Understanding}

Contextualized problems are presented in real-life situations and experiences that are familiar to the students. Concepts are presented in the context of their use and of what the student already knows.Contextual learning takes place when teachers are able to present information in a way that students are able to construct meaning based on their own experiences. Research suggests that contextualized problem solving have the potential to serve as foundational activities for mathematical learning. Students are meant to use their understanding of a problem situation to build informal representations that can serve as conceptual anchors for formal mathematical conventions and reasoning. It is meant to encompass a wide variety of tasks intended to provide students an opportunity to apply known procedures and examples but are still aimed at developing students' understanding of new mathematical concepts. As Bull et al. (2010) stated that students would solve problems based on their own prior understanding and knowledge until they could provide answers or interpretations. Thus, the teacher could identify concept that had been owned by them before they were introduced to formal concept. Bootge (1999) confirmed this through his study on the effects of contextualized mathematics instruction on problem solving of average and below - average achieving students which revealed that there was a significant difference on the scores of the students in contextualized problem and on the transfer task in both the remedial and pre-algebra classes. This study further supports the practice of situating problems in a meaningful context to improve the mathematics problem-solving skills of low and average achieving students. Perin (2011), in a study on facilitating student learning through contextualization also found out that practitioners who use contextualization observe positive results and the available quantitative evidence indicates that it has the potential to increase students' achievement.

The use of contextualized problems in mathematics exercises is anchored on Transfer of Learning Theory of Thorndike and Woodworth (1901) particularly on Identical Element Theory which states that transfer of learning is the dependency of human conduct, learning, or performance on prior experience. They explored how individuals would transfer learning in one context to another, similar context or how "improvement in one mental function" could influence a related one. Their theory implied that transfer of learning depends on how similar the learning task and transfer tasks are, or where identical elements are concerned in the influencing and influenced function. Transfer of learning is usually described as the process and the effective extension of past learning experiences to new situation. That is, students will connect what they learned before to perform new tasks and solve problems to a new situation similar to those which are found in textbook based problems.

Contextualized problem is also anchored in Situated Learning Theory developed by Lave and Wenger (1991). Particularly, it deals on ideas of "legitimate peripheral participation", which states that situated learning is usually unintended rather than methodical where students follow a step by step procedure and that learning normally occurs in the process of the activity, context and culture in which it occurs (i.e., it is situated). Answers of contextualized problems do not only use mathematical arguments but also require conceptual understanding that are generally practical, whose mathematical concepts could be learned in the context of the situation. Students are in a better position to understand abstract concepts if they are able to relate it to physical situations in their experience so they can develop conceptual understanding if lesson is contextualized.

Conceptual understanding means that students can clearly interpret, explain and apply the ideas that are important and they understand the value of those ideas. Students demonstrate conceptual understanding if they are able to identify and apply ideas to solve problems especially nonroutine problems and are able to explain their solutions (Wiggins, 2014). Cummings (2015) believed that if a student solves a problem and is able to answers a question why he does such process, he has conceptually understood the topic. To improve students' achievement in mathematics it needs one with a strong conceptual understanding. Good conceptual understanding could solve mathematics problem related to real life and could make decision critically. Hajiyati (2008) believed that a person would fail to answer application questions without good conceptual understanding and this is also supported by Subhan (2007) who stated that conceptual understanding is the ability to get meaning of an abstract idea until it could allow one to classify particular concepts.

A study conducted by Hidayat and Iksan (2015) using contextual problems or realistic mathematics education showed that the experimental group had a higher conceptual understanding than the control group. They showed more complete and correct answer according to context question and had more different answers than students taught by traditional approach. Hirschfeld-Cotton (2008) confirmed this through his investigation on the use of mathematical communication, and its impact on conceptual understanding and students' attitudes towards mathematics, and reported that there was an increased understanding that occurred through probing questions causing students to reflect on their learning and re-evaluate their reasoning. Students realized that true understanding did not come from mere homework completion, but from evaluating and assessing their own ideas and reasoning. It was further found out that when students were challenged to communicate their reasoning both orally and in writing, students enjoyed mathematics more and thought mathematics was more fun which resulted to positive attitudes toward mathematics. 


\section{International Journal of Science and Research (IJSR) ISSN (Online): 2319-7064}

Index Copernicus Value (2015): 78.96 Impact Factor (2015): 6.391

\subsection{Promoting Problem Solving through Contextualized Themes}

Zimbardo (1992) characterizes problem solving as thinking that is directed toward solving specific problems. For this reason, the presentation of the problem should be carefully crafted for students to grasp the meaning and for them to strategize how to solve such given problem. Laine, et al. (2012) claimed that the presentation of problem plays a central role in the problem solving lesson and that the introduction of the task with a representation seemed to be more successful than the other method. Hence, it is important that teachers should plan well the different problem solving activities so that they could give better guide to the students during the problem solving phase. Thus presenting problem solving exercises in contextualized manner would promote problem solving to students.

However, Buentipo's (2009) study on the problem solving difficulty in mathematics showed that the teaching strategies like drill, boardwork, seatwork and teachers' attitude and the mastery of the subject matter have caused the pupils difficulty in problem solving especially if they do not understand the concept. In addition, pupil's study habits, mathematical intelligence, comprehension skills and attitude towards problem solving have caused the problem solving difficulty. Hence, employing contextualized themes in problem solving exercises will help eased students' difficulty in problem solving to improve performance and develop desirable attitudes toward problem solving.

\subsection{Mathematics Anxiety}

Mathematics anxiety has been defined as feelings of tension and fear that interfere with the manipulation of numbers and the solving of mathematical problems in a wide variety of academic situations. It is experienced by many people in varied ways. Psychological indicators of mathematics anxiety include feelings of tension, fear and apprehension, low selfconfidence, a negative mind set towards mathematics learning, feeling threatened, failing to reach expectation, and a temporary reduction in working memory (Cavanagh and Sparrow, 2011). This may cause one to forget and lose one's self-confidence (Tobias, 1993). Clearly, mathematics anxiety can deter students' performance. It is further revealed that mathematics anxiety interferes with their ability to think and analyze mathematical problems posed to them and it hinders thought processes which are needed in problem solving.

As Dibaratum (2012) revealed that grade six pupils claimed that they had mathematics anxiety when they were attending their mathematics class. However, pupils were not afraid to ask questions during their mathematics class. Results also showed that students' fear was on the subject matter itself and not on the other factor like the mathematics teacher. Likewise, the study on mathematics self-efficacy and anxiety of May (2009) exposed that students who had passed in their examination were found to have a higher mathematics selfefficacy and lower mathematics anxiety than those students who had failed in the examination. This study revealed that if students' belief on one's self to succeed in a particular task is high then, students' anxiety is less. Clearly, mathematics anxiety affects their mathematics performance.

Moreover, Pagon (2013) discovered that there is a significant difference in the students' mathematics anxiety that were exposed to student-to-student discourse from those who were exposed to cooperative learning strategy. In addition, Parcutilo (2008) also found out that quiz buddy assessment had lowered level of anxiety in tests. These suggest that learning activities that emphasize the role of social and cultural context influenced mathematics anxiety as hypothesized by Siemens' (2005) connectivism theory. The theory purported that the particular value of the connectivism paradigm in mathematics and numeracy teaching lies in exploiting the properties of network connectivity in complex systems. By actively pursuing opportunities for students to link and promote an understanding of mathematics, this may help them to make connections through mappings of mathematical concepts with their varied skills and understandings of ideas around them. Connectivity is attained by linking mathematical knowledge, language and other skills from the student's existing knowledge that serves as building blocks for understanding and fluency. The use of rules is just consequences of the mathematics language rather than algorithmic procedures. He added that there is substantial merit in considering mathematics first as a language and focusing on ways and means to develop students' fluency while utilizing their existing skills and knowledge-base as leverage. With these, students gain confidence, overcoming their negative perceptions to support intrinsic motivation for pursuing further learning as an end in itself. Anxiety may never disappear entirely but future encounters with mathematics and frequent exposures of the students in solving problems, students may result in gaining confidence to perform any mathematical tasks which might lessen students' anxiety.

\section{Methodology}

This study used a pretest - posttest quasi-experimental control groups design. Two intact classes of second year Bachelor of Elementary Education (BEED) class of Western Mindanao State University (WMSU) External Studies Unit (ESU) Malangas Campus, Zamboanga Sibugay were randomly assigned as the experimental and control group.

To determine the effect of the treatment, the Problem Solving Test was used, composed of 10- item teacher made word problems. This test was designed to determine the achievement and conceptual understanding of the students in geometry, age, motion, work and mixture problem. The 20item constructed test was shown to three experts for face and content validation, and was tried out. Ten problems were accepted based with reliability coefficient of 0.83 . Students' answers in the problems were assessed and scored using the Northwest Regional Educational Laboratory Mathematics Problem Solving Model rubric with slight revision by McIntosh and Jarret (2000). The rubric has a highest possible score of four points with a descriptive rating of 'Exemplary' and the lowest score is one with a descriptive rating of 'Emerging'. The scores were obtained from the three raters. 


\section{International Journal of Science and Research (IJSR) \\ ISSN (Online): 2319-7064}

Index Copernicus Value (2015): 78.96 | Impact Factor (2015): 6.391

The problem solving test was scored based on the three facets of conceptual understanding, interpretation, application and explanation, based on the rubric by McTighe and Wiggins (1998). Each area has a highest possible score of four and the lowest score is one. An interview was done to six randomly chosen students from each group to validate findings.

The Mathematics Anxiety Questionnaire adapted from May (2009) was used to assess the level of mathematics anxiety of the participants with reliability index of 0.91 .

Table 1: Point Ranges for Mathematics Anxiety

\begin{tabular}{|c|c|}
\hline Point Ranges & Descriptive Interpretation \\
\hline $4.55-5.54$ & Very High \\
\hline $3.55-4.54$ & High \\
\hline $2.55-3.00$ & Mild \\
\hline $1.55-2.54$ & Low \\
\hline $0-1.54$ & Very Low \\
\hline
\end{tabular}

In the experimental group, the class started with a discussion on the basic steps on how to solve a problem. This was to equip students on how to solve problems that were presented in either contextualized or non-contextualized type. Contextualized problems were introduced first to the students that they solved through group activity. After doing the activity, students presented their output to the class followed by a class discussion to check the correctness of their solution. The remaining contextualized problem was given to the students as an assignment and was checked the next class session before the discussion of the remaining problems.

In the control group, students were taught using noncontextualized problems taken from the textbook. It started with a lecture discussion of the basic terms and steps in solving each type of problem. For the first two problems, students had to solve the problem first in their seats, then six randomly chosen students presented their solutions to the class. The other two problems were discussed through lectures and board works. The last problem was given as an assignment. After the types of problems were discussed, posttest was given to both experimental and control groups. The same Mathematics Anxiety Questionnaire was given to both control and experimental groups a day after the problem solving test was given. Finally, an interview was done to the students in the control and experimental groups to validate their conceptual understanding.

The Analysis of Covariance (ANCOVA) was used to analyze the effect of contextualized problems on students' achievement, conceptual understanding and mathematics anxiety. The ANCOVA was used because the samples were intact classes. This statistical tool adjusts the treatment effects with respect to the covariate collected before the experimental treatment. The basic technique incorporated in the ANCOVA was to remove the criterion measure which was predictable from covariate (Deauna, 1982). Lastly, Pearson Product Moment Correlation Coefficient was used to determine the relationship of students' achievement and their conceptual understanding. In testing the hypotheses, alpha was set at 0.05 level of significance.

\section{Results and Discussions}

The results of the analysis are shown in the following tables.

Table 2: Mean and Standard Deviation on the Level of Students' Achievement

\begin{tabular}{|c|c|c|c|c|c|c|c|c|}
\hline \multirow{3}{*}{$\begin{array}{c}\text { Problem } \\
\text { Type }\end{array}$} & \multicolumn{4}{|c|}{$\begin{array}{c}\text { Control group } \\
(n=35)\end{array}$} & \multicolumn{4}{|c|}{$\begin{array}{c}\text { Experimental group } \\
(n=35)\end{array}$} \\
\hline & \multicolumn{2}{|c|}{ Pretest } & \multicolumn{2}{|c|}{ Posttest } & \multicolumn{2}{|c|}{ Pretest } & \multicolumn{2}{|c|}{ Posttest } \\
\hline & $\bar{x}$ & $S D$ & $\bar{y}$ & $S D$ & $\overline{\bar{x}}$ & $S D$ & $\bar{y}$ & $S D$ \\
\hline Geometry & 0.96 & 0.9 & 3.08 & 1.38 & 1.1 & 0.82 & 4.26 & 1.13 \\
\hline Age & 1.14 & 1.06 & 3.06 & 1.47 & 0.98 & 0.62 & 4.06 & 1.07 \\
\hline Motion & 0.48 & 0.78 & 2.85 & 1.45 & 0.66 & 0.64 & 4.43 & 1.11 \\
\hline Work & 0.55 & 0.74 & 3.00 & 1.84 & 0.82 & 0.64 & 4.02 & 1.16 \\
\hline Mixture & 0.49 & 0.78 & 2.46 & 1.53 & 0.75 & 0.7 & 3.67 & 1.42 \\
\hline $\begin{array}{c}\text { Overall } \\
\text { Achievement }\end{array}$ & 3.63 & 3.49 & 14.43 & 6.31 & 4.31 & 2.29 & 20.4 & 4.06 \\
\hline $\begin{array}{c}\text { Level of } \\
\text { Students' } \\
\text { Achievement }\end{array}$ & \multicolumn{2}{|c|}{ Emerging } & \multicolumn{2}{|c|}{ Developing } & \multicolumn{2}{|c|}{ Emerging } & \multicolumn{2}{|c|}{ Proficient } \\
\hline
\end{tabular}

Table 2 shows the mean and standard deviation of each type of problems in the control and experimental groups. It can be seen in the pre-test that the control group of students have a higher score in age problem while the students in the experimental group have a higher score in geometry problem. This means that students from both groups had different backgrounds in problem solving. It can also be noticed that both groups got lowest scores in motion problems. This means that both groups of students did not possess sufficient prior knowledge on problems involving motion. The standard deviation for both groups suggests homogeneity in the knowledge about motion problem. This means that before the start of the study, the students from both groups had the same mathematical ability towards problem solving.

In the posttest, the control group got higher scores in geometry problem and the experimental group in motion problem. This means that students from the control group found geometry problem easier to comprehend and solve, while the experimental group of students understood well the motion problem. It can also be observed that the scores of the control group are slightly dispersed compared to the scores of the experimental group. The lowest mean score were recorded for both groups in mixture problem. This means that both groups find mixture problem most difficult to comprehend and solve. But, the scores of the students in the experimental group are higher than in the control group. This could also mean that the use of contextualized problems and the activity in the experimental group had in some way helped students understand the concept. The overall achievement level of students' achievement of the control group is 14.43 which is developing while the experimental group is already proficient with a mean of 20.42. This means that the used of contextualized problems had improved the problem solving ability of the students as compared to noncontextualized problems in the control group. It can also be seen that the standard deviation value of the control group is higher than the experimental group. This means that the scores of the students in the control group were widely dispersed than in the experimental group. 


\section{International Journal of Science and Research (IJSR) ISSN (Online): 2319-7064}

Index Copernicus Value (2015): 78.96 | Impact Factor (2015): 6.391

Table 3: Summary Table of One-way ANCOVA of Students' Achievement

\begin{tabular}{|c|c|c|c|c|c|}
\hline Source & $\begin{array}{c}\text { Adjusted } \\
\text { Sum of } \\
\text { Squares }\end{array}$ & Df & $\begin{array}{c}\text { Mean } \\
\text { Square }\end{array}$ & F-ratio & Probability \\
\hline $\begin{array}{c}\text { Treatment } \\
\text { effect }\end{array}$ & 456.96 & 1 & 456.96 & $29.85^{*}$ & .001 \\
\hline Error & 1025.88 & 67 & 15.31 & & \\
\hline Total & 1482.84 & 68 & & & \\
\hline
\end{tabular}

*Significant at 0.05

Table 3 shows the summary of the analysis of covariance of students' achievements' scores which yielded an F-ratio of 29.85 with a probability value of 0.001 lesser than 0.05 level of significance. This led to the non-acceptance of the null hypothesis. This implies that students' achievement mean score of the experimental group which is significantly higher than the control group mean score who were exposed to the problems in the textbook. This further implies that the use of contextualized problems in the experimental group had influenced a higher achievement of the students compared to the non- contextualized problems in the control group. The activity gave the students a first-hand experience in solving a problem, since the problems were contextualized and the local was familiar to the students. This helped them to relate the problem to their daily life. Students in the experimental group were able to construct meaning based on their own experiences in dealing with problems that were contextualized and helped them in transferring and applying the concept to new situation similar to the problems taken from the textbook.

This finding supports the theory of Thorndike and Woodworth (1901) on transfer of learning which states that transfer of learning depends on how similar the learning task whether situation are using identical elements in the influencing and influenced function. Transfer of learning is usually described as the process and the extent to which past experiences affect learning in a new situation. It also confirmed the study of Bootge (1999) on the effects of contextualized mathematics instruction on problem solving of average and below - average achieving students which revealed that there was a significant difference on the scores of the students in contextualized problem and on the transfer task in both the remedial and pre-algebra classes. This study further supports the practice of situating problems in a meaningful context to improve the mathematics problemsolving skills of low and average achieving students. The present study supports also Perin's (2011) study on facilitating student learning through contextualization based on the finding that practitioners who use contextualization observe positive results and the available quantitative evidence indicates that it has the potential to increase students' achievement.
Table 4: Mean and Standard Deviation on the Level of Conceptual Understanding

\begin{tabular}{|c|c|c|c|c|c|c|c|c|}
\hline \multirow{3}{*}{$\begin{array}{c}\text { Indicators of } \\
\text { Conceptual } \\
\text { Understanding }\end{array}$} & \multicolumn{4}{|c|}{ Control group $(n=35)$} & \multicolumn{4}{|c|}{$\begin{array}{c}\text { Experimental group } \\
(n=35)\end{array}$} \\
\hline & \multicolumn{2}{|c|}{ Pretest } & \multicolumn{2}{|c|}{ Posttest } & \multicolumn{2}{|c|}{ Pretest } & \multicolumn{2}{|c|}{ Posttest } \\
\hline & $\overline{\bar{x}}$ & $S D$ & $\overline{\bar{y}}$ & $S D$ & $\overline{\bar{x}}$ & $S D$ & $\bar{y}$ & $S D$ \\
\hline Interpretation & 0.9 & 1.4 & 6.4 & 4.4 & 1.3 & 1.2 & 13.7 & 5.3 \\
\hline Application & 3.2 & 4.3 & 7.7 & 6.8 & 2.5 & 2.8 & 16.2 & 4.3 \\
\hline Explanation & 0.09 & 0.3 & 0.9 & 2.1 & 0.06 & 0.2 & 1.2 & 2.4 \\
\hline Overall & 4.1 & 5.04 & 15.1 & 12.8 & 3.9 & 3.06 & 31.2 & 9.8 \\
\hline $\begin{array}{c}\text { Level of } \\
\text { Conceptual } \\
\text { Understanding }\end{array}$ & \multicolumn{2}{|c|}{ Weak } & \multicolumn{2}{|c|}{ Weak } & \multicolumn{2}{|c|}{ Weak } & \multicolumn{2}{|c|}{ Developing } \\
\hline
\end{tabular}

Table 4 shows the mean and standard deviation of the students' conceptual understanding in the pre-test and posttest. It can be gleaned from the table that both the control and experimental group of students in the pre-test have the lowest score in explanation. This is possible since students from both groups in the pre-test were not able to come up with a complete and correct answer. The standard deviation of the control group for explanation facet also revealed that both groups had a homogeneous distribution of scores. Both groups got high score in application. This means that both students manifested little prior knowledge before the discussion of the topic. Although the control group mean score is quite higher than the experimental group, their performance under this facet was still weak. The standard deviation of the control group is higher than the experimental group standard deviation, meaning the control group scores were more dispersed than the scores of the students in the experimental group. Both groups in the pretest were weak in terms of their conceptual understanding.

In the posttest, both control and experimental groups have a highest mean score in application this indicates that students from both groups were able to apply the different concepts learned during the discussions. It can also be observed that during the posttest the mean of the experimental group for the application facet is already higher than the control group by 8.52 . This means that students were able to apply the concepts better from their experiences in dealing with contextualized problems rather than non- contextualized problems. The standard deviation of the control is higher than the experimental group; this means that the control group of students' scores were more dispersed than the experimental group. The lowest score for both groups is in explanation, this means that after the discussion and the implementation of the treatment, students still found it hard to explain their solution. This low score is a manifestation that the students had poor idea about what they were doing. This was validated by their solution to the problem of which most of the students did not explain their answer since most of them did not come up with the correct answer. The overall level of conceptual understanding of the control group after the discussion of the topics was still weak as reflected in a mean score of 15.09, while the experimental group's level of conceptual understanding after the treatment shows that it was already developing as indicated in its mean of 31.20. This means that the use of contextualized problems had improved students' ability to interpret, apply and explain their solutions to the problem compared with the control

\section{Volume 6 Issue 7, July 2017} www.ijsr.net 


\section{International Journal of Science and Research (IJSR) \\ ISSN (Online): 2319-7064}

Index Copernicus Value (2015): 78.96 Impact Factor (2015): 6.391

group who were exposed to non-contextualized problems. This is possible since during the activity students had the opportunity to directly manipulate the objects use and they were able to understand the concept a bit. The overall standard deviation of the control group is higher than the experimental group. This means that the scores of the control group were more scattered than the scores of the students in the experimental group.

Table 5: Summary Table of One-way ANCOVA of Conceptual Understanding

\begin{tabular}{|c|c|c|c|c|c|}
\hline Source & $\begin{array}{c}\text { Adjusted Sum } \\
\text { of Squares }\end{array}$ & $d f$ & $\begin{array}{c}\text { Mean } \\
\text { Square }\end{array}$ & F-ratio & Probability \\
\hline $\begin{array}{c}\text { Treatment } \\
\text { effect }\end{array}$ & 4831.03 & 1 & 4831.03 & $64.34 *$ & .001 \\
\hline Error within & 5031.16 & 67 & 75.09 & & \\
\hline Total & 9862.19 & 68 & & & \\
\hline
\end{tabular}

*Significant at 0.05

Table 5 shows the result of the analysis using one way ANCOVA. It yielded a computed F- ratio of 64.34 and a probability value of 0.001 which is lesser than alpha level 0.05 . Thus, there is enough evidence not to accept the null hypothesis. This means that there exists a significant difference in the mean score of students' conceptual understanding. This implies that the conceptual understanding of the experimental group who underwent contextualized problem solving process is significantly higher than the control group with a mean score after the treatment. This further implies that students in the experimental group could demonstrate better understanding in applying concepts, interpreting with sense the given facts and situations and explaining the concepts of how and why the process worked using their own words, teaching to others, justifying why their answers are correct.

This finding agrees with the study conducted by Hidayat and Iksan, (2015) using contextual problems or realistic mathematics education to enhance student conceptual understanding of mathematics. The answer of the experimental group showed that the students had a better conceptual understanding than the control group. They showed more complete answers although their answers were not perfect.

It also supported the findings of Hirschfeld-Cotton (2008), on the use of mathematical communication, and its impact on conceptual understanding and students' attitudes towards mathematics which revealed that there was an increased understanding through probing questions causing students to reflect on their learning and re-evaluate their reasoning. Students realized that true understanding did not come from mere homework completion, but from evaluating and assessing their own ideas and reasoning. The study challenged the students to communicate their reasoning both orally and in writing to enjoy mathematics more such that it would have positive attitudes toward mathematics.

Figure 1 below presents the solutions of the low performing students from both groups in the pretest in problem 6 . The first angle of a triangle is 4 times the result of decreasing the second angle by $15^{\circ}$. The third angle is 3 times the second angle. How many degrees are there in each angle?

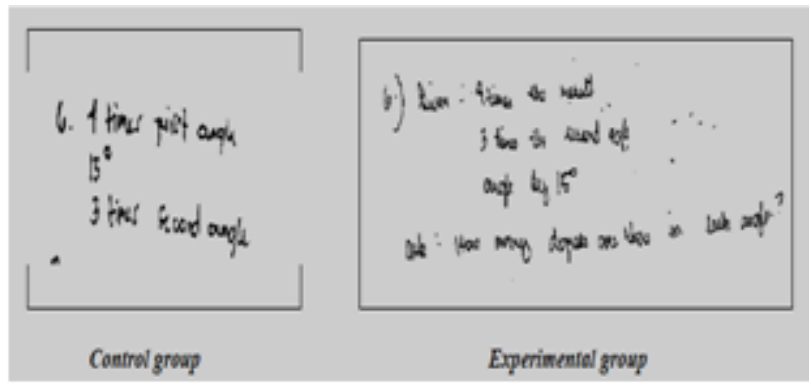

Figure 1: Pre-test solutions of low performing students on conceptual understanding

It can be seen in the solution of the students from both groups that they only listed down the given facts, although it was incorrectly done. They did not even attempt to solve the problem. There was no evidence that students possessed the skill of illustrating the problem through a figure for better understanding. They did not possess prior knowledge of the problem. It showed no application of the previously learned concept and they did not try to solve the problem.

Figure 2 below shows the solutions of the average performing students from the control and experimental groups in problem 4. It takes 10 hours for Franz to make a bench. If Kenneth and Franz work together they can do the job in 4 hours. How long would it take Kenneth to make a bench alone?

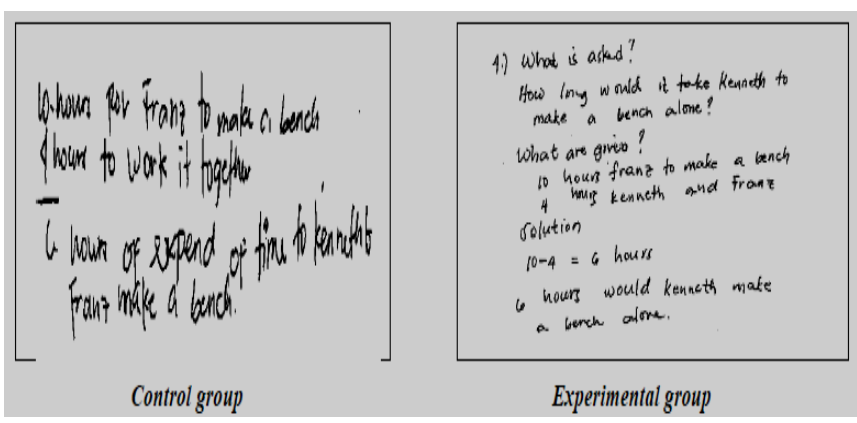

Figure 2: Pre-test solutions of average performing students on conceptual understanding

The solution shown by average students from both groups indicate that they did not possess the skills in interpreting the problem through an illustration; the students from the control group and experimental group simply subtracted the given working hours together from the working hours of Franz. This means that students had no background on work problem. They both arrived at the wrong answer. The student in the experimental group tried to distinguish what was asked and what were the given in the problem, but did not make representation for the unknown variable, did not attempt to interpret, did not attempt to explain the reason for the equation that was written and did not apply the concept involved.

Figure 3 below presents the pretest solution of the high performing students from both groups in problem 5. How 


\section{International Journal of Science and Research (IJSR) \\ ISSN (Online): 2319-7064}

Index Copernicus Value (2015): 78.96 | Impact Factor (2015): 6.391

much water must be evaporated from 15 liters of $12 \%$ lye solution to obtain a solution of $20 \%$ lye.

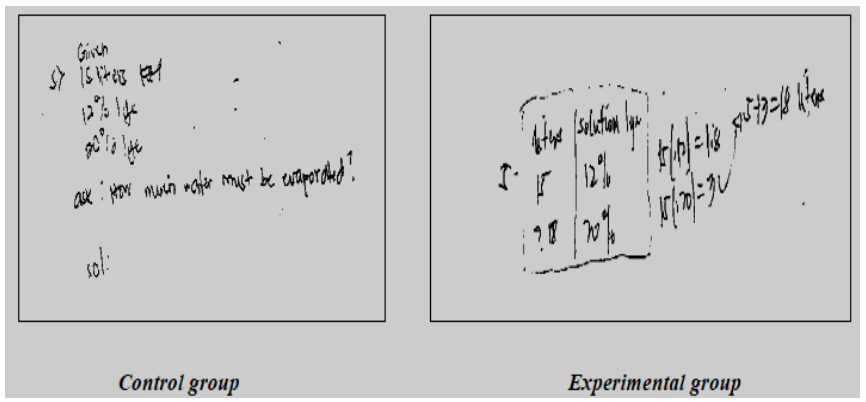

Figure 3: Pre-test solutions of high performing students on conceptual understanding

It is observed that the student in the control group did not interpret the problem through an illustration, image or table; there was no solution to the problem; she just listed down the given facts and identified what was asked in the problem. There was no evidence that this student understood the problem and did not possess no prior knowledge involving mixture problem. There was no attempt to solve the problem, no attempt to explain what she was doing. While the student in the experimental group attempted to interpret the problem by constructing a table to represent the unknown variable. There is slight evidence that the student had a prior knowledge because of her attempt to use table of the given data but she failed to interpret the problem. However, her answer was wrong and there was no explanation on how she got the answer.

"I encountered similar topic on this ma'am in high school but, I can no longer recall them, because in the first place wala sad ko naka sabot atonga time pagdiscuss. That is why, dili gyud nako ma solve ang problem". [I encountered similar topic on this ma'am in high school but, I can no longer recall them, because in the first place I really did not understand the topic well during the discussion]. CGAM\#1

"My solution is just by chance because I was not able to recall what I previously learned. I can only recall concepts discussed in the past if they were thoroughly understood by me." EGHF\#1

"I cannot explain it ma'am because I do not have an answer. I can only explain if my answer is correct kung sure gyud ko nga correct ako answer ma'am." [I cannot explain it ma'am because I do not have an answer. I can only explain if my answer is correct if I am certain of my answer ma'am]. EGHM\#2

It can be seen from the solutions of the students in the pretest from both groups that they did not possess conceptual understanding. Clearly, the students had the same level of conceptual understanding before the discussion and before the start of the treatment.

Figure 4 below shows the solutions of the low performing students from both groups in the posttest in problem 6 . The first angle of a triangle is 4 times the result of decreasing the second angle by $15^{\circ}$. The third angle is 3 times the second angle. How many degrees are there in each angle?

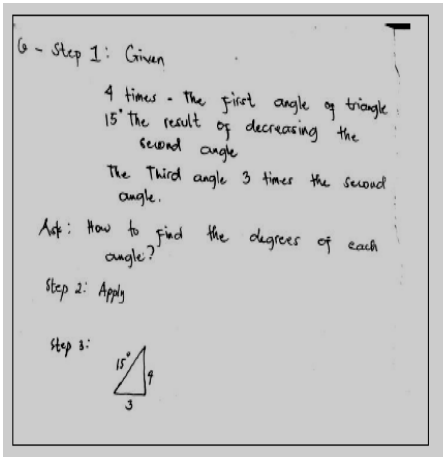

Control group

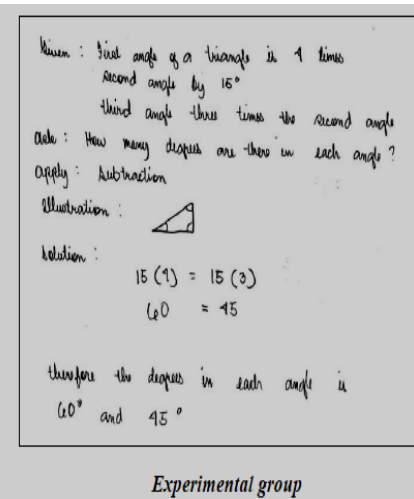

Experimental group
Figure 4: Posttest solutions of low performing students on conceptual understanding

After the discussion of the topics, the solution of the student in the control was still the same prior to the discussion. Although, there was an effort of trying to interpret the problem through a figure but the label was not correct. There was no evidence that the student conceptually understood the topic since the student did not have a solution. She was not able to apply the concepts learned during their discussion. Furthermore, there was no justification or explanation of her work. On the other hand, the student in the experimental group showed the same attempt to illustrate the problem after the treatment using contextualized problems. Although, she still did not get the correct picture of the statement in the problem. She tried to apply what she seemed to learn from the discussion to a new and complex situation but she still got the wrong answer. Moreover, she did not explain her answer to show that the problem made sense to her.

Figure 5 below presents the solution of the average students from both groups in problem 4. It takes 10 hours for Franz to make a bench. If Kenneth and Franz work together they can do the job in 4 hours. How long would it take Kenneth to make a bench alone?

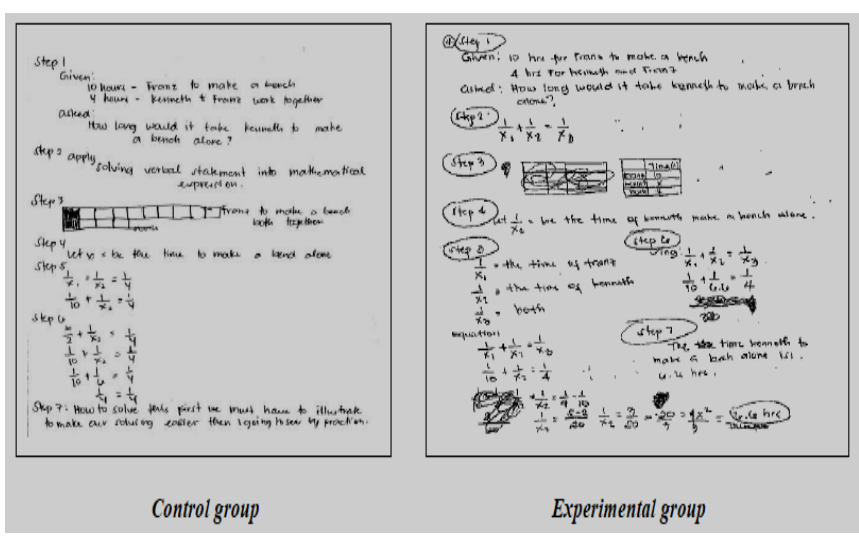

Figure 5: Posttest solutions of average performing students on conceptual understanding

The students from both groups exhibited some skills such as interpreting the problem through a figure to visualize the problem properly, the knowledge on what concepts to apply to solve the problem, and an attempt to explain their solution. However, the student in the control group was not able to 


\section{International Journal of Science and Research (IJSR) \\ ISSN (Online): 2319-7064}

Index Copernicus Value (2015): 78.96 Impact Factor (2015): 6.391

show the correct mathematical representations. There was an incorrect application of the concepts problem on the application of the concepts previously learned during discussion as evidenced in the construction of the equation. His solution did not follow logically as was discussed in the previous steps.

Meanwhile, the student in the experimental group was able to show the mathematical representations and used the correct equation, the solution to the problem was logically implemented in each step and the answer was correct. This could mean that student who was exposed to contextualized problems had a better conceptual understanding and possessed the ability to transfer the concepts previously learned compared to the student who was not exposed to it.

Figure 6 presents the solution of the high performing students from both groups in problem 5 . How much water must be evaporated from 15 liters of $12 \%$ lye solution to obtain a solution of $20 \%$ lye.

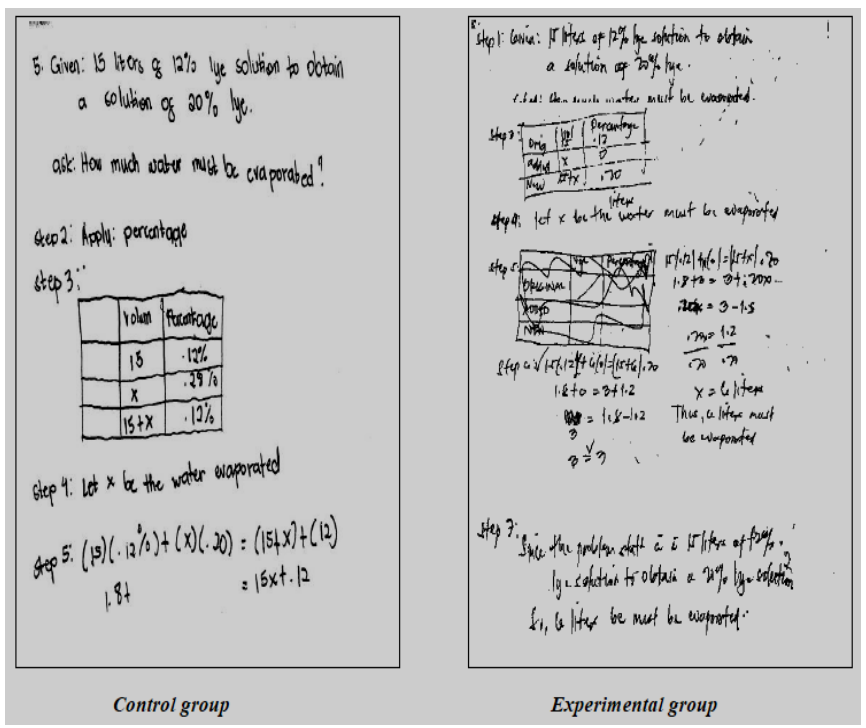

Figure 6: Posttest solutions of high performing students on conceptual understanding

It can be gleaned from the figure that both students illustrated the problem through a table and represented the problem in mathematical statement. The illustration of the student in the control group was still incorrect; the concepts applied were only partially correct. On the other hand, the student in the experimental group was not able to interpret the problem perfectly because the portion which is represented by $x$ in the solution that has evaporated is already pure water, not lye, but the evaporated portion which is $x$ was added. The answer is correct but the solution is wrong. This could mean that student in the experimental group exhibited conceptual understanding but the answer did not make sense because the result was negative. He applied the concepts incorrectly which were discussed during the lesson proper of the contextualized problem, but the evaporation was wrongly interpreted. The learning experiences had helped students in some way improved their conceptual understanding but with some misinterpretation of the problem. They applied the concepts, justified their answers and wrote their reason.
"Gi base nako sa unkown sa problem ma'am. Katong formula nga similar sa atong gi-discuss[I based on the unknown of the problem ma'am. The formula which was similar during our discussion]. But, during the test ma'am, I was mental block for a few minutes. But, I really forced myself to recall the previous concept and apply them at the same time." EGLF\#2

"My illustration is based on the situation or what is asked in the problem. I really tried my very best ma'am to illustrate the problem so I can have a better picture of the problem and so that I can also understand more the problem". EGHF\#1

Based on the students' answers in the interview it could be assumed that when students experienced problem of similar situation, it gave them insights to other problem with some resemblance of their experience.

However, after the discussion of the topics, the level of conceptual understanding of the control group was still weak. This was validated through their responses in the interview.

"I was mental blocked and bothered ma'am during the test when I read all the problems together. Sayang kayo ma'am kay similar ra biya unta sa atonga nadiscuss, [I found the problem very similar to what we discussed] but still I was not able to recall them". CGAF\#2

"Ma'am I cannot really explain if my answer is correct because in the first place I am sure that it is wrong, because when I do the checking the answer in the equation is not equal. CGHM\#1

The answers of the students in the interview clearly showed that students had difficulty in recalling concepts and deriving a correct solution. These are manifestations that students did not thoroughly understand the concepts taught since they could not still answer the problem that was similar to the problem presented.

Table 6: Mean and Standard Deviation of Mathematics Anxiety

\begin{tabular}{|c|c|c|c|c|}
\hline & \multicolumn{2}{|c|}{ Experimental Group } & \multicolumn{2}{c|}{ Control Group } \\
\hline & Pretest & Posttest & Pretest & Posttest \\
\hline Mean & 3.74 & 2.86 & 3.69 & 3.89 \\
\hline SD & 0.53 & 0.39 & 0.73 & 0.74 \\
\hline Level of Anxiety & High & Mild & High & High \\
\hline
\end{tabular}

Table 6 shows the mean and standard deviation of students' mathematics anxiety from both groups in the pretest and posttest scores. It reveals that the level of anxiety of the students from both groups was high prior to the discussion of the topics. The experimental group exhibited more fear compared to the control group. It can be gleaned from the computed standard deviation that the scores of the control group were slightly dispersed from each other compared to the experimental group although the scores of the students were close to each other.

In the posttest, it can be observed that the level of anxiety of the students in the control group is still high and higher than 


\section{International Journal of Science and Research (IJSR) \\ ISSN (Online): 2319-7064}

Index Copernicus Value (2015): 78.96 | Impact Factor (2015): 6.391

the level of anxiety of the experimental group which is described as mild. The standard deviation of the control group is higher compared to the standard deviation of the experimental group, meaning that the scores of the students in the control group were more dispersed than the scores of the students in the experimental group. The experimental group of students had reduced anxiety and was more homogeneous. A noticeable increase of mean in the pretest of the control group which is 3.69 to a mean of 3.89 in the posttest could be attributed to the difficulty of the topic, the type of problems and students' prior knowledge.

Table 7: Summary of One Way ANCOVA of Mathematics

\begin{tabular}{|c|c|c|c|c|c|}
\hline Source & $\begin{array}{c}\text { Type III } \\
\text { Sum of } \\
\text { Squares }\end{array}$ & Df & $\begin{array}{c}\text { Mean } \\
\text { Square }\end{array}$ & F-ratio & Probability \\
\hline Treatment effect & 19.61 & 1 & 19.61 & $81.71 *$ & 0.001 \\
\hline Error within & 15.91 & 67 & 0.24 & & \\
\hline Total & 35.52 & 68 & & & \\
\hline *Significant at 0.05
\end{tabular}

Table 7 shows the result of the analysis of the students' responses on the anxiety questionnaire yielded a computed Fratio value of 81.71 and a probability value of 0.001 which is lesser than 0.05 level of significance. This led to the nonacceptance of the null hypothesis. This implies that students' mathematics anxiety differed as an effect of the problem solving approach. The level of students' anxiety in the control group is significantly higher than the level of anxiety of the students in the experimental group. This means that the use of contextualized problems in the experimental group through group activity was effective in reducing anxiety of the students towards mathematics, while the usual problem solving approach had increased their anxiety. The contextualized problem solving could have good effect on their feeling towards mathematics because the situation was familiar to them. In addition, they could also ask questions freely without fear and tension towards their classmates while working on the activity. There was social interaction and cooperation among the students which led to a feeling of confidence that enhanced their understanding of the concept. This situation may not be the same in the traditional lecture method because generally the interaction happens only between the teacher and students.

Table 8: Correlations of Students' Achievement and Conceptual Understanding

\begin{tabular}{|c|c|c|c|c|c|}
\hline Group & & Achievement & $\begin{array}{c}\text { Conceptual } \\
\text { Understanding }\end{array}$ & $r$ & Probability \\
\hline \multirow{4}{*}{$\begin{array}{l}\text { Control } \\
\text { Group }\end{array}$} & $\bar{x}$ & 3.63 & 4.14 & \multirow{2}{*}{$0.95 *$} & \multirow{2}{*}{0.001} \\
\hline & SD & 3.49 & 5.04 & & \\
\hline & $\bar{y}$ & 14.43 & 15.09 & \multirow{2}{*}{$0.92 *$} & \multirow{2}{*}{0.001} \\
\hline & SD & 6.31 & 12.79 & & \\
\hline \multirow{4}{*}{$\begin{array}{c}\text { Experi- } \\
\text { mental } \\
\text { Group }\end{array}$} & $\bar{x}$ & 4.31 & 3.86 & \multirow{2}{*}{$0.80 *$} & \multirow{2}{*}{0.001} \\
\hline & SD & 2.29 & 3.06 & & \\
\hline & $\bar{y}$ & 20.42 & 31.20 & \multirow{2}{*}{$0.89 *$} & \multirow{2}{*}{0.001} \\
\hline & SD & 4.06 & 9.76 & & \\
\hline
\end{tabular}

*Significant at 0.05

Table 8 shows the results of the analysis using Pearson r. In the pretest, the control group has a computed $r$ value of 0.95 which denotes a very high relationship with a probability value of 0.001 which is lesser than alpha 0.05 . The result revealed that there is enough evidence not to accept the null hypothesis. This implies that there is a significant relationship between students' achievement and their conceptual understanding. This implies further that if students are low in their achievement, their conceptual understanding is also low.

In the posttest, the control group of students has a computed $r$ value of 0.92 which denotes a very high relationship and a probability value of 0.001 which is lesser than alpha 0.05 . There is enough evidence not to accept the null hypothesis. Thus, there is a significant relationship between students' achievement and their conceptual understanding. This implies that after the discussion of the topics, students' achievement was still very highly correlated with their conceptual understanding.

Similarly, the experimental group in the pretest has a computed $r$ value of 0.80 which denote high correlation and a probability value of 0.001 which is lesser than alpha level at 0.05 . Thus, there is enough evidence not to accept the null hypothesis. Hence, there is a significant relationship between students' achievement and their conceptual understanding. This implies that students' achievement and conceptual understanding were both at the lowest level before the implementation of the treatment.

In the posttest, the experimental group of students has a computed $r$ value of 0.89 which denotes high relationship and a probability value of 0.001 which is lesser than alpha 0.05 . The results led to the non-acceptance of the null hypothesis. This implies that students' posttest achievement significantly relates to their posttest conceptual understanding. This further implies that if students conceptually understood the problem well their achievement was also high. Since students' achievement had increased, their conceptual understanding had also increased. It can be noted that the conceptual understanding had increased from weak to developing. Hence, the use of contextualized problems helped students conceptually understand the problems because the objects and places were community- based and they could easily relate the problem to their daily life.

\section{Conclusion and Recommendations}

Based on the findings of the study, the researchers conclude that contextualized problem is effective in enhancing students' achievement and conceptual understanding, reduced students' anxiety towards mathematics, and that students' achievement is significantly related to their conceptual understanding. Hence, the researchers recommend the use of contextualized problem as teaching strategy. Parallel study may be conducted in the future to a wider scope using other disciplines for better generalization.

\section{References}

[1] Bootge, B.A.(1999). Effects of Contextualized Math Instruction on Problem Solving of Average and Below-

\section{Volume 6 Issue 7, July 2017 www.ijsr.net}




\section{International Journal of Science and Research (IJSR) \\ ISSN (Online): 2319-7064}

Index Copernicus Value (2015): 78.96 | Impact Factor (2015): 6.391

Average Achieving Students. The Journal of Special Education Vol.33/No.2/1999/PP.8192.http://sed.sagepub.com/content/33/2/81.abstract

[2] Buentipo, L. D. (2009). Problem Solving Difficulty in Mathematics Among Grade V Pupils in Public Elementary Schools of Catarman District. Thesis. Camiguin Polytechnic State College

[3] Bull, S., Jackson, T. J., \& Lancaster, M. J. (2010). Students' Interest in Their Misconceptions in First Year Electrical Circuits and Mathematics Courses. International Journal of Electrical Engineering Education, $\quad 47, \quad 307-318$. http://dx.doi.org/10.7227/IJEEE.47.3.6

[4] Cavanagh, R. \& Sparrow, L. (2011). Mathematics Anxiety: Scaffolding a New Construct Model. Mathematics Traditions and [New] Practices, (C) AAMT \& MERGA

[5] Cummings, K. (2015). How Does Tutoring to Develop Conceptual Understanding Impact Student Understanding?, Honors Program Theses and Projects. Virtual Commons - Bridgewater State University

[6] Deauna, M. (1982). Applied Statistics for Education Psychology and the Social Sciences. Integrated Research Center.De la Salle University. Taft Avenue Manila.

[7] Dibaratum, J. B., (2012). Mathematics Anxiety Among Grade Six Pupils. Thesis: St. Peters College, Iligan City

[8] Dreger RM , Aiken LR (1957) The Identification of Number Anxiety in a College Population. J Educational Psychology, 47: 344-351

[9] Freudenthal, H. (1991). Revisiting mathematics education: China lectures. Springer.

[10] Go Silk, C.J.(2012). Cognitive and Metacognitive Skills in Solving Worded Problems in Algebra: An Analysis. Thesis: Western Mindanao State University.

[11] Go Silk, C.J.,Go Silk, B.B. \& Somblingo, R. A.(2015). Teaching Problem Solving: A Metacognitive Process. Institutional Project: Western Mindanao State University.

[12] Hajiyati, S. (2008). Peningkatan pemahaman konsep simteri melalui model pembelajaran kreatif dengan permainan matematik. Skripsi, Sukoharjo: Universitas Muhammadiyah Surakarta.

[13] Hidayat,R. and Iksan, Z. H. (2015). The Effect of Realistic Mathematic Education on Students' Conceptual Understanding of Linear Progamming. Published Paper. Faculty of Education, Universiti Kebangsaan Malaysia, Bangi, Malaysia. Scientific Research Publishing Inc.

[14] Hirschfeld-Cotton, K. (2008), Mathematical Communication, Conceptual Understanding, and Students' Attitudes Toward Mathematics . Action ResearchProjects.Paper4.http://digitalcommons.unl.edu/ mathmidactionresearch $/ 4$

[15] Hudson, P. J., Miller, S. P., \& Butler, D. L. (2006). Adapting and merging explicit instruction within reform based mathematics classrooms. American Secondary Education, 35(1), 19-32

[16] Laine, A. et al (2012). Third-graders' Problem Solving Performance and Teachers' Actions . Published Paper. University of Helsinki, Department of Teacher Education. Umeå Mathematics Education Research Centre, UMERC. ISBN: 978-91-7459-556-7
[17]Lave, J., \& Wenger, E. (1991). Situated learning: Legitimate peripheral participation. Cambridge university press.

[18]May, D. K. (2009). Mathematics Self-Efficacy and Anxiety Questionnaire. Unpublished Dissertation.The University of Georgia

[19] McIntosh, R. and Jarrett, D. (2000) Teaching Mathematical Problem Solving: Implementing the Vision -A Literature Review. Retrieved May 23, 2008 from

http://www.nwrel.org/msec/images/mpm/pdf/monograph .pdf,

[20] National Council of Teachers of Mathematics (2000) Principles and Standards for School Mathematics. Reston, VA: NCTM.

[21] Pagon, R. C. (2013). Student-to-Student Discourse On Selected Topics in Algebra: Its Effects to Student Achievement and Mathematics Anxiety. Mindanao university of Science and Technology. Cagayan De Oro City.

[22] Parcutilo, J. O. (2008). Quiz Buddy: A Pair Assessment and Its Influence on Students Performance in Calculus and On Mathematics and Test Anxiety. Thesis: Mindanao Polytechnic State College, Cagayan de Oro City

[23]Perin, D. (2011)Facilitating Student Learning Through Contextualization. Community College Research Center. Teachers College, Columbia University. http://ccrc.tc.columbia.edu/media/k2/attachments/facilita ting-learning-contextualization-working-paper.pdf

[24]PISA (2003) Problem Solving for tomorrow's world: First measure of cross-curricular competencies from Programme for International Student Assessment

[25]Richardson FC, Suinn RM (1972) The Mathematics Anxiety Rating Scale: Psychometric Data. J Counseling Psychology, 19: 39-47

[26] Sherman HJ, Richardson, LI, Yard GJ (2014) Why Do Students Struggle with Mathematics, Allyn and Bacon, an imprint of Pearson Education Inc.

[27] Siemens, George (2005). "MOOC or MegaConnectivism Course". Retrieved from http://en.wikipedia.org/wiki/Connectivism

[28] Subhan, A. (2007). Meningkatkan pemahaman konsep dan sikap peserta didik melalui pelatihan guru dengan VCD pemodelan dan pendampingan pada pembelajaran matematik bercirikan pendayagunaan alat peraga bahan pengahajarn pokok luas bangun datar kelas V SD Sekaran 2 TA 2006/2007. Skripsi, Malang dan Blitar: Unversiti Negeri Malang.

[29] Thorndike, E. L. and Woodworth, R. S. (1901) "The influence of improvement in one mental function upon the efficiency of other functions", Psychological Review 8:

[30] Tobias, S. (1993). Overcoming math anxiety. New York: W. W. Norton \& Company.

[31] Wiggins, G., \& McTighe, J. (1998). Understanding by Design . Alexandria , VA : Association for Supervision and Curriculum Development.

[32] Wiggins, G. (2014). Conceptual Understanding in Mathematics.

https:/grantwiggins.wordpress.com/2014/04/23/concept ual-understanding-in-mathematics/

\section{Volume 6 Issue 7, July 2017 www.ijsr.net}


[33]Zimbardo, P. (1992) Psychology and Life (13th ed.). HarperCollins Publishers Inc., N.Y.

[34]M. Clerc, "The Swarm and the Queen: Towards a Deterministic and Adaptive Particle Swarm Optimization," In Proceedings of the IEEE Congress on Evolutionary Computation (CEC), pp. 1951-1957, 1999. (conference style)

[35]H.H. Crokell, "Specialization and International Competitiveness," in Managing the Multinational Subsidiary, H. Etemad and L. S, Sulude (eds.), CroomHelm, London, 1986. (book chapter style)

[36] K. Deb, S. Agrawal, A. Pratab, T. Meyarivan, “A Fast Elitist Non-dominated Sorting Genetic Algorithms for Multiobjective Optimization: NSGA II," KanGAL report 200001, Indian Institute of Technology, Kanpur, India, 2000. (technical report style)

[37] J. Geralds, "Sega Ends Production of Dreamcast," vnunet.com, para. 2, Jan. 31, 2001. [Online]. Available: http://nl1.vnunet.com/news/1116995. [Accessed: Sept. 12, 2004]. (General Internet site)

\section{Author Profile}

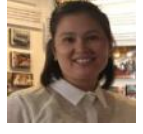

Laila S. Lomibao received her BS Physics for Teachers from Philippine Normal University, MSciEd in Physics from Mindanao State University-Iligan Institute of Technology and $\mathrm{PhD}$ in mathematical Science major in Mathematics Education from Mindanao University of Science and technology. Currently, she is the chairperson of the Department of Mathematics Education of the University of Science and Technology of Southern Philippines (USTP), College of Science and Technology Education.

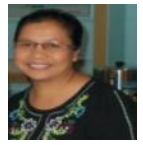

Carmela J. Go Silk is a faculty of the College of Science and Mathematics of Western Mindanao State University-Malangas Campus, Zamboanga Sibugay. Dr. Go Silk received her PhD in mathematical Science major in Mathematics Education from USTP and her MST Mathematics and BS Mathematics from Western Mindanao State University main campus.

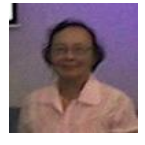

Charita A. Luna is a professor emeritus of Mindanao University of Science and Technology now University of Science and Technology of Southern Philippines. She had presented a number of research papers in mathematics education in national and international conferences and had published numerous papers in international indexed journals. 